\title{
The Impact of Cloud Computing and Organizational Sustainability
}

\author{
Dr Tomayess Issa \\ Curtin University of Technology \\ GPO Box U1987 \\ Perth WA 6845 \\ 61892667682 \\ Tomayess.Issa@cbs.cutin.edu.au
}

\author{
Associate Professor Vanessa \\ Chang \\ Curtin University of Technology \\ GPO Box U1987 \\ Perth WA 6845 \\ 61892664487 \\ Vanessa.Chang@cbs.curtin.edu.au
}

\author{
Dr Theodora Issa \\ Curtin University of Technology \\ GPO Box U1987 \\ Perth WA 6845 \\ 61892667725 \\ Theodora.Issa@cbs.curtin.edu.au
}

\begin{abstract}
When economic times get tough, businesses worldwide are compel to review their organizational expenses and priorities and to strategically consider how best to save. Traditionally, Information Technology (IT) department is one area that would be affected negatively in the review. To better serve the organization and clients and for business to continue to increase productivity, it is important to understand which technology investments might allow for cost reduction and efficient use of resources. Continuing to fund these strategic technologies during an economic downturn is vital to organizations. It is predicted that in coming years IT resources will only be available online. More and more organizations are looking at operating smarter businesses by investigating technologies such as cloud computing, virtualization and green IT to find ways to cut costs and increase efficiencies.
\end{abstract}

'Cloud computing' is one recent phenomenon which is predominantly driven by industry recognition of the triple bottom line making sustainability their focus. This is also driven by industry needs that may have the ability to transform the work place, with a focus on capital expenditure, infrastructure, applications, usage, mobility, and cost structure. The attraction of cloud computing is obvious with noticeable freedom from managing and hosting applications, platforms, and infrastructure. Though advantages of cloud computing are countless, cloud computing is still in its infancy and has disadvantages such as security, privacy, reliability, physical location of data and the unavailability of service due to crashes or bugs in providers' storages; the consequences of which are merely unknown. These disadvantages might be tackled through the proper introduction, training and implementation of codes of ethics as guiding principle to those involved in the usage of cloud computing in business.

This paper provides a brief literature review of cloud computing, followed by an analysis of the cloud-computing environment using the PESTEL framework. The future implications and limitations of adopting cloud computing as an effective ecofriendly strategy to reduce carbon footprint are also discussed in the paper. This paper concludes with a recommendation to guide researchers to further examine this phenomenon.

\section{Keywords}

Could Computing, Sustainability, Ethics, Security, Adoption, Carbon Footprint

\section{INTRODUCTION - ORGANIZATIONS' SOCIAL RESPONSIBILITY}

Greenfield (2004) argued that, amid the Tyco, Worldcom, and Enron furor, organizations ought to reflect rather than commit to a 'quick fix' or a 'band aid' solution. Past experiences had demonstrated that business solutions that organizations take were usually based on the assumptions that (1) debacles in the financial markets and (2) loss of confidence in business stem from failures in the corporate governance system. Goldsmith and Samson (2006) posit that with the shift in the role of business combined with the changing business environment and growing community concerns, there are increasing pressure for organizations to pursue sustainable development strategies. Organizations are faced with the challenge of balancing the demands of global competition and sustainable development. Many organizations are investing resources to create organizational strategies to tackle today's business environment (Jacobides 2010). Globalization, technological innovation, regulatory restructuring, demographic shifts, and environmental pressures have all conspired to continually redraw the competitive landscape. Compounded by issues affecting the environment, organizations making business decisions and solutions must take into account their corporate social responsibility instead of focusing solely on the bottom line of generating revenue and increasing profit. While making profit is a priority to all organizations, it is critical that modern-day organizations exercise their corporate social responsibility by focusing on people and the planet.

Kolstad (2007) stated that though corporate social responsibility is on the agenda of most major corporations, corporate executives still largely support the view that corporations should maximize the returns to their owners. There are two justification for this, (1) the Friedmanian view that maximizing owner returns is the social responsibility of corporations, and (2) a position voiced by many executives, that corporate social responsibility and profits go together. Executives conclude that there may be good reasons for firms to deviate from a maxim of profit maximization. Valentine and Fleischman (2008) summed up that corporate social responsibility is juxtaposition between ethics program variables and individual job satisfaction which suggest that companies might better manage employees' ethical perceptions and work attitudes.

Annual International Conference on Cloud Computing and Virtualization (CCV 2010).

Edited by Prof. Gagan Agrawal.

Copyright (c) CCV 2010 \& GSTF.

ISBN: 978-981-08-5864-3.

doi:10.5176/978-981-08-5837-7_185 
Kleinrichert (2008) contended that the commitment to corporate social responsibility is a source of power, as well as an ethical practice for corporate endeavors. Kleinrichert concluded that re-establishing strong relationships with the community could be developed by revisiting corporate social responsibility. In practice, managers should support this by publishing the organization's code of ethics and conducts. Chonko and Wotruba (2003) argued that when managers are familiar with the code's content and intentions, the managers' behavior and outlook are positive and they are more thoughtful in their decision-making. Chonko and Wotruba, (2003) in their study explored whether the impact of code familiarity on code usefulness differs in the following ways: (a) under varying conditions of turbulence and (b) between persons with relativist versus idealist personal values. They concluded that perceptions of ethics code familiarity and usefulness decline as business turbulence increases. The decline in familiarity/usefulness was more pronounced for managers with a relativistic ethical orientation. Though there are attempts to introduce codes of ethics to organizations to exercise corporate social responsibility in order to address today's global economy, there is no immediate indication that we are taking advantage of this.

Some scholars, academics and practitioners argue that the design of and training on codes of ethics would address the problems that the society or the global economy is facing. Some researchers indicated that a document that prescribes behaviors is not a code of ethics because it precludes empowerment to make the ethical decisions. Others consider prescriptive documents to be 'best practice' for codes of ethics. Farrell, Cobbin and Farrell (2002) indicated that there is a distinction between prescriptive and inspirational code types, and this classification becomes a focal point on what is the appropriate subject matter for a code of ethics. When designing a code of ethics, organizations are required to consider the usefulness of the code; and later implement the code so that employees are familiar with the business practices. The recent summit in Copenhagen to engage the world on climate change should provoke countries, governments, businesses, communities, and individuals to participate in taking more social responsibilities of the planet. All businesses and professions have very similar code of ethics embracing knowledge, trust, and integrity to uphold the profession. Given the recent publicity of Greenhouse Effect and Climate Change (n.d.), organizations are acutely aware of their corporate social responsibility.

As indicated previously, organizations today have acted swiftly to incorporate Green IT as part of the organizations' business practice. Many organizations have incorporated technology that simultaneously offers services and greening facility. Adoption of cloud computing into the organization's business activities is also increasing. Adopting this technology offers various benefits in electric power reduction consumption of IT hardware. Cloud computing promises many technological and sociological benefits, and it is also touted for its ability to address the need for energy efficiency (Stewart \& Kennedy 2009). In a number of recent studies, cloud computing promises to provide better performance, reliability and scalability e.g., (Armbrust et al. 2009); (Erdogmus 2009). Cloud computing also attract the recognition of being ethically responsible and ensuring that organizations are becoming more sustainable (Newton 2003). A strategy to incorporate and implement effective cloud computing services is required for all organizations. This strategy must also ensure that professionals who implement cloud computing services have a set of useful code of ethics and conducts; and that they become familiar with the codes to ensure better dealings at all avenues. A number of professionals' ethical code of conduct already exists and organizations ought to re-visit the codes to ensure that they are adhered to. An example is that of the Information Systems (IS) professionals' ethical code of conduct. Oz (1992, p. 431- 432) stated that, "IS professionals in one country do not differ from their colleagues in other countries, and they are all expected to abide by the same standards of practice, regardless of organizational or national affiliation. This is especially true in the reality of a "global village, where computer networks diminish the importance of national borders". In addition, "technology, does not stand 'outside' of society ... but instead, technology - its manufacturers, benefactors, users-is a social phenomenon itself, subject to all the constraints of other social actors. Among these constraints is the notion of social responsibility: You can and will be held accountable for your actions" (Laudon 1995, p. 38).

\section{BENEFITS OF SUSTAINABLE DEVELOPMENT STRATEGIES}

As mentioned previously, the adoption of the new cloud computing services and technology will assist in the reduction of capital expenditure and carbon footprint (Grossman 2009), and therefore highlights the importance of sustainable corporate responsibility. Herbert and Erickson (2009) contended that the realization of cloud computing in businesses may eliminate the need for full time help desk and server support. This will have a major influence on reducing the cost and allowing the deployment of these staff into 'white collar' roles. This may also gives rise to challenges such as compensation for providers who offer services to external users (Buyya et al. 2009).

Incorporating sustainable strategy with emerging technologies is becoming the norms in contemporary businesses (Newton 2003). To do this effectively, Young and Tilley (2006) proposed an integrated model of corporate sustainability which links together six criteria that a sustainable business will need to satisfy. The six criteria are (1) eco-efficiency, (2) socio-efficiency, (3) eco-effectiveness, (4) socio-effectiveness, (5) sufficiency and (6) ecological equity. However, further theoretical development is still underway to have an effective integrated approach to apply the six criteria. Erek et al. (2009, p.2) confirmed that "sustainability has been extensively discussed within corporate management under the synonyms of corporate social responsibility (CSR), greening the business eco-efficiency or ecoadvantage". To ensure that organizations develop and adhere to a sustainable development strategy, management should consider aspects of value creation that would benefit its employees, users and stakeholders by encouraging all participants to be environmentally and socially responsible corporate citizens.

\section{INFRASTRUCTURE OF CLOUD COMPUTING}

Currently various facilities are available on the Internet to allow users to maintain their data and applications by using 
Internet and central servers, and this service is called Cloud Computing. Smith $(2009$, p.66) define Cloud Computing as a "style of computing where massively scalable IT-related capabilities are provided as a service across the Internet to multiple external customers". This simply means users will be renting computers, storage and network capacity on hourly basis from companies who provide this technology on the Internet. This service is available any time and from anywhere across the world. Lawson (2009, p.10) confirms that "cloud computing and flash-based storage, two fast-emerging IT technologies, are driving each other forward as users of Internet-based services like social networks demand near-real-time access to ever growing amounts of data".

Cloud Computing is developed from the virtualization of Infrastructure as Service (IaaS), Software as a Service (SaaS), and Platform as a Service (PaaS) (Vaquero et al. 2009). The IaaS service manages a "large set of computing resources such as sorting and processing capacity through virtualization", which will allow them to "split, assign and dynamically resize these resources to build ad-hoc systems as demanded by customers" (Vaquero et al. 2009, p. 50-51). SaaS service stand that when the software is running over the Internet and the access is via a browser (Schneier 2009), while the PaaS is a "platform in the cloud, upon which applications can be developed and executed" (Schulz 2009). These infrastructures offer services to users in different areas based on their requirements and needs. An example of companies who are already established in the on-Demand Software or SaaS service are Salesforce.com (CRM), Google (GOOG), NetSuite(N), Taleo(TLEO), and Concur Technologies (CNQR) (Cleveland \& Lewis 2009).

Conry-Murray (2009, p.37) listed some Cloud Computing providers who support a variety of Operating Systems, Web Servers and databases and physical resources "into discrete chunks that can be allocated to one or many customers". These providers such as Amazon.com, AT\&T, GNi, IBM, Rackspace, Savvis, ServePath, Skytap, 3Tera, Unisys, Verizon and Zimory provide their server pricing from 10 cents per hour to $\$ 5,700$ per annum.

Gilman (2009, p.22) stated that with cloud computing "new products or services can be added without the usual accompanying investment in new infrastructure, training, or software licensing". In addition, Weier (2009b, p.40) stated that this technology is also "becoming more of a business function that helps drive efficiencies in building these apps and consuming services via the cloud". However, Gilman (2009) and Babcock (2009) indicated that as this technology evolves, the services will offer greater storage capacity, faster speed, and more intuitive user interface.

Rival competitions are pushing the cloud technology to the next level with Weier (2009a, p.18) reported that Google is offering Google Apps - Gmail Calendar, Docs, Sites Web pages, and Postini e-mail security facilities to users at a fee of $\$ 50$ per annum. In return, by mid-2010 Microsoft is planning to offer the same technology - MS Word, Excel, PowerPoint and One Note at no charge to its customers. To counter this, Google is planning to design a "set of cloud services for Federal government agencies [to] give them a boost in its effort to take on Microsoft Corp. on the desktop" (Gaudin 2009, p.8).

\section{ADVANTAGES AND DISADVANTAGES OF CLOUD COMPUTING}

Cloud computing has a number of business benefits, in that it is dynamically scalable, the resources can be purchased with operational funds rather than as a capital expenditure, and the equipment does not reside at the organization's facility (Smith 2009). Furthermore, cloud computing "has 'green' credentials as long as the location of the storage and hardware premise uses renewable sources of energy" (Bateman \& Wood 2009, p.1475). Provided that the premise is eco-friendly, users using the cloud computing technology can reduce hardware usage, as this technology "indirectly helps to reduce the environment destruction" (Bajgoric 2010, p.227). Vykoukal, Wolf \& Beck (2009) argued that the cloud technology plays an important role for organization in reducing the accumulation of greenhouse gases by reducing the $\mathrm{CO}_{2}$ emissions. This is vital considering the various negative impacts from rising costs of waste disposal, corporate image and public perception (Vykoukal, Wolf \& Beck 2009).

As there are a myriad of providers of cloud computing, an important strategy for organizations is to select providers that adhere to corporate social responsibility and providers who are active participants of the sustainable responsible business ethics. Smith (2009, p. 67) advocated that "if the first provider does not deliver acceptable performance a company can always shift its business to another company offering better service or lower prices."

Albeit its advantages, there are concerns in relation to security and the physical location of data. There are also issues pertaining to unavailability of service due to crashes or bugs in the providers' storage and privacy and control issues of data residing at third party's network. It is also clear that educating the communities and businesses require time and effort; and the shift will not happen overnight (Preston 2008). Although the up-take is slow, there are those organizations who are leading the way in using cloud computing services and technologies.

\section{PESTEL FRAMEWORK AND TRIPLE BOTTOM LINE}

In order to gauge the effectiveness of adopting cloud computing in organizations, the main research question to be asked is "Why would organization consider the adoption of cloud computing services and technology?" In order to discuss this research question, the PESTEL framework of political, economic, social, technological, environmental and legal will be used to analyze the adoption of Cloud Computing and its impact of the triple bottom line. The PESTEL framework is a "mnemonic used in strategic management to group macro-environment factors to help strategists look for sources of general opportunity and risks" (Witcher \& Chau 2010, p.91). The PESTEL framework analyzes the external business environment to understand the 'big picture' in which the organization operates thus enabling them to take advantage of the opportunities and minimize the threats faced by the organization's business activities (Mind Tools, n.d.). In this regard, the PESTEL analysis is used in this research to allow the organizations to understand the big picture of adopting cloud 


\section{Annual International Conference on Cloud Computing and Virtualization (CCV 2010)}

computing in the business environment and to realize the advantages, opportunities and to minimize the threats of this technology.

This PESTEL framework of the six factors will be analyzed as follows:

\subsection{Political}

The political factor is concerned with government regulations and legal issues that organizations must adhere to. From the political perspective, organizations must consider laws and regulations for their own countries. As cloud computing is decentralized with readily available data, the access, use of these services may evolve into borderless jurisdiction in the cloud, and organizations need to separate its business dealings and functions from its legal implications. As data stored within a cloud can be stored in different countries, and may be transmitted to computers in different geographic locations, the information may be subject to the laws of the specific location of the physical computer that holds the data. As recently reported, "countries like China and the United States are making laws that are having a negative ripple effect on the development of the global cloud, and thus a negative effect on the enrichment of the global economy" (Poston 2008). The same report and in another source (Baker 2008, p.5) claimed that the Canadian government has asked organizations "not to use computers in the global network that are operating within United States borders because the Canadian data stored on those computers could conceivably be negatively impacted by the repercussions of the Patriot Act".

\subsection{Economic}

The economic factor is concerned with the cost-related matters for the organization (Witcher \& Chau 2010). From an economic perspective, organizations that adopt cloud computing for their business activities will expect a reduction in their capital expenditure. As corporate executives have a responsibility in maximizing returns to their owners, new technologies such as cloud computing may alleviate the tight budget of any organizations. As pointed out by Hickey (2010), the "research points to government interest in software-as-a-service solutions, cloud computing, virtualization and social networking initiatives as evidence of the need to meet the dual goals of containing costs and modernizing technology". While cloud computing requires very little capital investment, businesses will incur organizational costs in the form of payment for a cloud computing provider's service. The methods of payment vary, but they can be categorized into two types: utility-based and subscription-based. Under this method, businesses will only be required to pay for cloud computing resources that they utilize (Hamm 2008). On the other hand, a subscription-based payment involves a predetermined amount of money to be paid on a monthly or annual basis (Salesforce.com, n.d.). A sustainable business strategy must also be developed to ascertain that credible providers are selected to provide the cloud services. If a credible provider provides alternative to the organization's internal platforms and applications - one that requires no capital outlays, long-term contracts, data-center infrastructure or internal IT staff - users can scale the service up or down according to their business needs. Clearly, cloud computing - as a purely on demand service-delivery model - is tailor-made for a bubble economy" (Kobielus 2008, p.22).

\subsection{Social}

The social factor is related to changes to the enterprises by adopting the cloud computing technology. The social aspect includes consumer awareness, citizens' attitudes and individual practices of using services on the cloud. Organizations and employees must adhere to a set of guiding principle or code of ethics; and to be aware of the value of information stored on the cloud, e.g. the value of personal information, disclosure of personal information and uses of personal data. Privacy issues and different level of data sensitivity (e.g. financial data, payroll/HR data, employment history, medical history, etc) must also be considered when implementing the use of cloud services. In addition to the above aspects, culture within the organization also forms part of this factor. The transition to cloud computing may affect employee's job security as management decide to strategize further costs cutting and its effects on employee morale may be detrimental to securing future profit. It is important that executive consider this aspect as part of the business sustainable development plan.

\subsection{Technological}

In addition to cutting capital expenses, adopting cloudcomputing technology has many advantages, for example the availability, durability, flexibility and mobility of the cloud provide infinite data resources and storage (Jha, Merzky \& Fox 2009 , p.1093). Users are able to access information conveniently on demand at anywhere and anytime. The unit cost for cloudbased "services is often lower than the cost if the services were provided directly by the organization itself" (Grossman 2009, p.25). Furthermore, cloud computing "resources can be purchased with optional funds, rather than as a capital expenditure" (Smith 2009, p.67), and users do not wait for the installation and implementation of their equipment since this technology is readily available online. This technology provides outstanding performance at maximum cost and "company can always shift its business to another company offering better service or lower prices" (Smith 2009, p.67).

\subsection{Environmental}

With growing sensitivity toward environmental issues, companies are increasingly expected to take greater responsibility for making sustainable development a reality. However, defining this new role is a major challenge for companies as they search for ways to balance economic, environmental and social performance. To integrate sustainability principles into their business strategies and to aid resource allocation decisions, managers must quantify the link between environmental actions and financial performance. Epstein and Roy (2003) have proposed a framework that might assist managers in making the "business case' for sustainability initiatives. Within the context of that framework, they examined a sample of corporate sustainability reports to (1) determine whether companies have been measuring the financial impact of environmental and social initiatives, (2) identify specific areas of concern and obstacles to the integration of sustainability into corporate performance and (3) provide 


\section{Annual International Conference on Cloud Computing and Virtualization (CCV 2010)}

specific guidance as to how companies can move toward a better integration of environmental and social initiatives in their decision-making processes and operations. The results suggested that companies are increasingly attempting to link environmental initiatives to financial performance. While environmentally responsible organizations are aware of the hypes surrounding cloud computing and climate change, green energy and related topics, many organizations are yet to commit to a clear business case for the broader issue of sustainability.

\subsection{Legal}

One of the biggest concerns is the storage of sensitive data (i.e. customer information, employee records) on the cloud, which warrants ethical and privacy considerations. Users are concern if their "sensitive data were fall into the wrong hands" (Preston 2008, p.52). A number of business decisions had considered security in the cloud as the top reason that holds back many from using the cloud (Barman 2008, p.35). From an ethics point of view, a company that stores data in a cloud computing provider's data center gives rise to the possibility for the provider to access or tamper with company data. Likewise, from a privacy point of view, storing customer information and employee records on the cloud may put a company at risk for possible legal action if that information is made public or is used in an otherwise unauthorized manner. The use of computing best practice such as data migration with strong authentication and guiding principles of IT use should continue to apply in the cloud (McGarvey 2008, p.11). Organizations must also consider service-level agreements (SLAs) with cloud computing services providers. If there is a security failure in the cloud that may compromise users' data, the organization must comply legally to notify users under state or federal law (Chong et al. 2009). Protection of Intellectual Property (IP) must also be considered in cloud computing.

It is an attempt in this paper to introduce the services and technology of cloud computing to be a critical part of the triple bottom line. The "triple-bottom line" concept provides a framework to companies to measure and report their performance and organizational success in relation to the three pillars of 'people, planet, and profit'. The primary objective of a corporate sustainability program is to account for the triple bottom line. Erek et al. (2009) stated that corporate sustainability is about minimizing a business' negative impacts on people, societies and the environment while maintaining or enhancing value for customers, business partners and shareholders. From the business perspective, "sustainability is mainly equated with the economical or financial sustainability. However, integrated corporate sustainability is achieved by recognizing the interdependence of the three dimensions over time and keeping an optimal balance between them" (Erek et al. 2009, p.2).

The case of introducing the triple-bottom line and caring for the environment, people in addition to profit, might be difficult for some organizations to absorb when the mindsets of executives may have been tainted with the importance of profit. Alexander (2007) contends that there is a systemic condition inherent in contemporary markets that compel managers not to pursue more morally preferred initiatives if those initiatives require actions that conflict with profit maximization. To overcome this constraint Alexander (2007) argues we must elevate a more normatively preferable value, ideal environmental sustainability, to the level of being the primary filtering value through which other competing values are evaluated, prioritized, and implemented. In order for this to occur in practice, a change must be made relative to the laws, rules, and regulations that define and guide the market.

Elliot (2007, p.106) stated the Australian national government policy encourages triple bottom line reporting one government agency expressed concern that "effective triple bottom line reporting could not be undertaken until the ICT industry makes available better information to support government reporting requirements." Triple bottom line reporting remains voluntary for Australian Government agencies. Currently the Australian government is working very closely with a high level of ICT and stakeholders across the states to consider "how to better manage and reduce the environmental impacts, including energy consumption, from using ICT" (Elliot 2007, p.104). However, it is up to the ICT industry to "address environmental considerations for manufacturing, product use, design and disposal" (Elliot 2007, p.104).

\section{CONCLUSION}

This paper discussed the concepts and benefits cloud computing in organizations. This technology has positive aspects and has a direct impact on sustainability and reduction in carbon footprint. Although many organizations embrace social responsibility, are aware of climate change, and green IT, many are not exploring this technology. To ensure that cloud computing is well implemented; organizations need to consider plan to incorporate business sustainability development strategy in the organization.

The PESTEL framework was used to analyze some of the issues surrounding the adoption of cloud computing services and technology. Not only that there is urgency for corporations to be environmentally savvy, but there is also an urgent need for institutions and academics to join in the cause to prepare and educate the future generations. Hammond and Churchman (2008) propose that universities incorporate principles of social sustainability in the planning and change management policies and processes. They recognize the importance of social sustainability in higher education courses. Arlow (1991) provides an empirical evidence that there is a greater need to focus business ethics instruction based on student characteristics. Those students are the leaders of the future, thus need to be educated to be the force for change in the organization, and society as a whole. As a start, the researchers will be trialing a course that will be offered to post graduate students on the environmental, economic, and social benefits of cloud computing in organizations, and in the future, a similar course will be offered to the industry to encourage the adoption of cloud computing in their businesses. 


\section{REFERENCES}

[1] Alexander, J 2007, 'Environmental Sustainability Versus Profit Maximization: Overcoming Systemic Constraints on Implementing Normatively Preferable Alternatives', Journal of Business Ethics, vol. 76, no. 2, pp. 155-162. Springer 2007.

[2] Arlow, P 1991, 'Personal Characteristics in College Students' Evaluations of Business Ethics and Corporate Social Responsibility', Journal of Business Ethics, vol. 10, no. 1, pp. 63-69. Retrieved: January 1991, from ABI inform.

[3] Armbrust, M, Fox, A, Griffith, R, Joseph, AD, Katz, R, Konwinski, A, Lee, G, Patterson, D, Rabkin, A, Stoica, I \& Zaharia, M 2009, Above the Clouds: A View of Cloud Computing. Retrieved: 1 Dec 2009, from http://radlab.cs.berkeley.edu/w/uploads/2/24/9_Above the Clouds_A_View_of_Cloud_Computing_pdf.

[4] Babcock, C 2009, 'Hybrid Clouds', Information Week, vol 1240, p. 15. Retrieved: 9 October 2009, from ABI/INFORM Global.

[5] Bajgoric, N 2010, Always-on Enterprise Information Systems for Business Continuance: Technologies for Reliable and Scalable Operations, IGI Global, USA.

[6] Baker, P 2008, The Cloud: Saving Grace or Empty Thunder? , Internet.com.

[7] Barman, B 2008, 'Safe on the Cloud', in Siliconindia, pp. 34 35 ,

[8] Bateman, A \& Wood, M 2009, 'Cloud Computing', Bioinformatics, vol. 25, no. 12, p. 1475

[9] Buyya, R, Yeo, CS, Venugopal, S, Broberg, J \& Brandic, I 2009, 'Cloud Computing and emerging IT Platforms: Vision, hype, and reality for delivering computing as the 5th utility', Future Generation Computer Systems, vol. 25, pp. $599-616$.

[10] Chong, F, Miguel, A, Hogg, J, Homann, U, Zwiefel, B, Garber, D, Joseph, J, Zimmerman, S \& Kaufman, S 2009, Design Considerations for $S+S$ and Cloud Computing. Retrieved: 1 March 2010, from http://msdn.microsoft.com/enus/architecture/aa699439.aspx.

[11] Chonko, LB \& Wotruba, TR 2003, 'Ethics code familiarity and usefulness: Views on idealist and relativist managers under varying conditions of turbulence', Journal of Business Ethics, vol. 42, no. 1. Retrieved: 2003, from ABI inform.

[12] Cleveland, D \& Lewis, A 2009, Cloud Computing. Retrieved: 9 October 2009, from http://www.Wikinvest.com.

[13] Conry-Murray, A 2009, 'What's In The Public Cloud', Information Week, vol. 1240, p. 37. Retrieved: 9 October 2009, from ABI/INFORM Global.

[14] Elliot, S 2007, 'Environmentally Sustainable ICT: A Critical Topic for IS Research?', in Pacific Asia Conference on Information Systems, pp. 100 - 112.

[15] Epstein, MJ \& Roy, M-J 2003, 'Making the Business Case for Sustainability: Linking Social and Environmental Actions to Financial Performance', The Journal of Corporate Citizenship, no. 9, pp. 79-96.
[16] Erdogmus, H 2009, 'Cloud Computing: Does Nirvana Hide Behind the Nebula?', IEE Software, vol. 26, no. 2, p. 4.

[17] Erek, K, Schmidt, N-H, Zarnekow, R \& Kolbe, LM 2009, 'Sustainability in Information Systems: Assortment of Current Practices in IS Organizations', in Americas Conference on Information Systems (AMCIS), pp. 1-9.

[18] Farrell, BJ, Cobbin, DM \& Farrell, HM 2002, 'Codes of ethics: Their evolution, development and other controversies', Journal of Management Development, vol. 21, no. 2, pp. 152-163.

[19] Gaudin, S 2009, 'Fed Plan Helps Google in Cloud Race With Microsoft', ComputerWorld, vol. 43, no. 29, p. 8. Retrieved: 9 October, from ABI/INFORM Global.

[20] Gilman, R 2009, 'Cleaning Confusion on Cloud Computing', American Agent \& Broker, vol. 81, no. 9, p. 22. Retrieved: 9 October 2009, from ABI/INFORM Global.

[21] Goldsmith, S \& Samson, D 2006, Sustainable Development and Business Success, Thomson, Melbourne.

[22] Greenfield, WM 2004, 'Attention to people and principles is key to corporate governance and ethics', Employment Relations Today, vol. 30, no. 4, pp. 1-10. Retrieved: 11th November 2009, from ABI/INFORM Global.

[23] Grossman, RL 2009, 'The Case for Cloud Computing', Computer.org/ITPro, pp. 23 -27.

[24] Hamm, S 2008, Cloud Computing: Eyes on the Skies. Retrieved: 1 March 2010, from http://www.businessweek.com/magazine/content/08 18/ b4082059989191.htm.

[25] Hammond, C \& Churchman, D 2008, 'Sustaining academic life: A case for applying principles of social sustainability to the academic profession', International Journal of Sustainability in Higher Education, vol. 9 , no. 3, pp. 235-245. Retrieved: 18th September 2008, from ProQuest.

[26] Herbert, L \& Erickson, J 2009, The ROI Of Software-As-AService, Forrester.

[27] Hickey, K 2010, Study gauges interest in cloud computing, green IT. Retrieved: 1 March 2010, from http://gcn.com/Articles/2010/02/16/Study-gaugesinterest-in-cloud-computing-green-IT.aspx.

[28] Jacobides, M 2010, 'Strategy Tools for a Shifting Landscape', Harvard Business Review, vol. 77, no. January/February, pp. 77 - 84.

[29] Jha, S, Merzky, A \& Fox, G 2009, 'Using Clouds to Provide Grids with Higher levels of Abstraction and explicit support for usage modes', Concurrency Computat: Pract. Exper, vol. 21, pp. 1087 -1108.

[30] Kleinrichert, D 2008, 'Ethics, Power and Communities: Corporate Social Responsibility Revisited', Journal of Business Ethics, vol. 78, pp. 475 - 485.

[31] Kobielus, J 2008, 'Cloud Computing in a Bubble Economy', in Networkworld.com, p. 22, 15 December 2008.

[32] Kolstad, I 2007, 'Why Firms Should Not Always Maximize Profits', Journal of Business Ethics, vol. 76, pp. 137145. Springer 2007.

[33] Laudon, KC 1995, 'Ethical Concepts and Information Technology', Communications of the ACM, vol. 38, no. 12 , pp. 33 - 39.

[34] Lawson, S 2009, 'The Cloud Could Be a Boon for Flash Storage', ComputerWorld, vol. 43, no. 26, p. 10. Retrieved: 9 October 2009, from ABI/INFORM Global. 
[35] McGarvey, R 2008, Three Steps to Secure Cloud Computing, Internet.com.

[36] Newton, LH 2003, Ethics and Sustainability, Sustainable Development and the Moral Life, Prentice-Hall, Inc., New Jersey.

[37] Oz, E 1992, 'Ethical Standards for Information Systems Professionals: A Case for a Unified Code', MIS Quarterly, vol. 16, no. December, pp. 423 - 433.

[38] Poston, L 2008, Computers Without Borders: Cloud Computing and Political Manipulation. Retrieved: 15 Dec 2009, from http://profy.com/2008/05/25/cloudcomputingpolitics/.

[39] Preston, R 2008, 'Will Cloud Computing Rain On IT's Parade?', Information Week, vol. 1173, p. 52.

[40] Schneier, B 2009, Be Careful when you come to put your trust in the clouds, Guardian. Retrieved: 15 Feb 2010, from http://cacm.acm.org/magazines/2009/5/24642-therise-fall-and-resurrection-of-software-as-aservice/fulltext.

[41] Schulz, W 2009, What is SaaS, Cloud Computing, PaaS and IaaS? Retrieved: 15 Feb 2010, from http://www.sconsult.com/2009/08/04/what-is-saas-cloud-computingpaas-and-iaas/.

[42] Smith, R 2009, 'Computing in the Cloud', ed. RT Management. Industrial Research Institute, Inc., pp. 65 68 ,

[43] Stewart, E \& Kennedy, J 2009, The Sustainability Potential of Cloud Computing: Smarter Design. Retrieved: 1 Dec 2009, from

http://www.environmentalleader.com/2009/07/20/thesustainability-potential-of-cloud-computing-smarterdesign/.

[44] Valentine, S \& Fleischman, G 2008, 'Ethics Programs, Perceived Corporate Social Responsibility and Job Satisfaction', Journal of Business Ethics, vol. 77, no. 2, pp. 159 - 172.

[45] Vaquero, LM, Rodero-Merino, L, Caceres, J \& Lindner, M 2009, 'A Break in the Clouds: Towards a Cloud Definition', ACM SIGCOMM Computer Communication Review, vol. 39, no. 1, pp. 50 - 55.

[46] Vykoukal, J, Wolf, M \& Beck, R 2009, 'Does Green IT Matter? Analysis of the Relationship between Green IT and Grid Technology from a Resource-Based View Perspective', in Pacific Asia Conference on Information Systems (PACIS).

[47] Weier, MH 2009a, 'Microsoft, Google Ready To Square Off', Information Week, vol. 1239, p. 18. Retrieved: 9 October 2009, from ABI/INFORM Global.

[48] Weier, MH 2009b, 'SaaS Leader Practices What It Preaches', Information Week, vol. 1241. Retrieved: 9 October 2009, from ABI/INFORM Global.

[49] Witcher, BJ \& Chau, VS 2010, Strategic Management Principles and Practice, Cengage Learning EMEA, United Kingdom.

[50] Young, W \& Tilley, F 2006, 'Can Businesses Move Beyond Efficiency? The Shift toward effectiveness and Equity in the Corporate Sustainability Debate', Business Strategy and the Environment, vol. 15, pp. 402-415. Retrieved: 21st January 2010, from InterScience. 